\title{
Endoscopic ultrasound-guided gastrojejunostomy as a rescue therapy for gastric outlet obstruction in a patient with multiple previous procedures
}

Endoscopic ultrasound-guided gastroenterostomy (EUS-GE) is a new minimally invasive alternative for palliation of malignant gastric outlet obstruction (GOO) $[1,2]$. However, data are lacking about its feasibility and safety in patients with previous EUS-guided biliary procedures or surgical jejunostomy.

A 57-year-old woman presenting with a locally advanced pancreatic cancer was referred to our department because of GOO. An uncovered duodenal stent of $12 \mathrm{~cm}$ was placed. Subsequently, the patient developed acute cholangitis and an EUS-guided hepaticogastrostomy was performed using a partially covered 10-cm self-expanding metal stent (SEMS; Hanarostent; MI-Tech, Gyeonggi-do, Rep. of Korea) combined with an antegrade fully covered stent ( $\triangleright$ Fig. 1 ). Both treatments were effective; however, 6 months later, she developed a new episode of GOO due to occlusion of the duodenal stent. A surgical jejunostomy was carried out, but the improvement was moderate, and the patient expressed her desire to eat by mouth. Meanwhile, she underwent two exploratory laparoscopies without evidence of carcinosis.

It was decided to perform an EUS-GE despite the suspicion of fixed proximal jejunal loops and the long duodenal stent covering almost all of the angle of Treitz. First, a 7-Fr canula was passed through the duodenal stent using a colonoscope. Two contrast injections and careful water instillation were performed through the catheter and the surgical jejunostomy ( Fig.2). Second, the echoendoscope was positioned facing the angle of Treitz and the optimal proximal jejunal loop segment was chosen, paying attention to the position of the distal end of the duodenal stent. The hepaticogastrostomy was placed far away in the proximal stomach. A hybrid technique using a 20-mm lumen-apposing metal stent (LAMS; Hot AXIOS; Boston Scientific, Voisins-le-Bretonneux, France) with a pre-

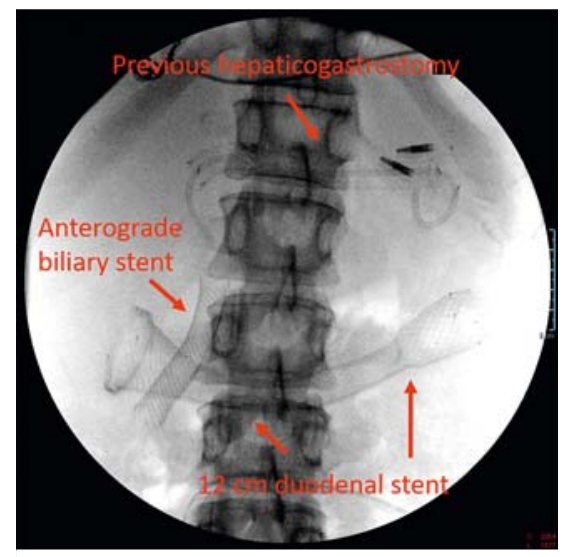

- Fig. 1 Radiographic image showing the previous hepaticogastrostomy with a $10-\mathrm{cm}$ partially covered metal stent and a 7-Fr, 5-cm double-pigtail plastic stent (a clip is observed in the proximal end), along with a transpapillary fully covered metal stent, and a $12-\mathrm{cm}$ duodenal stent.

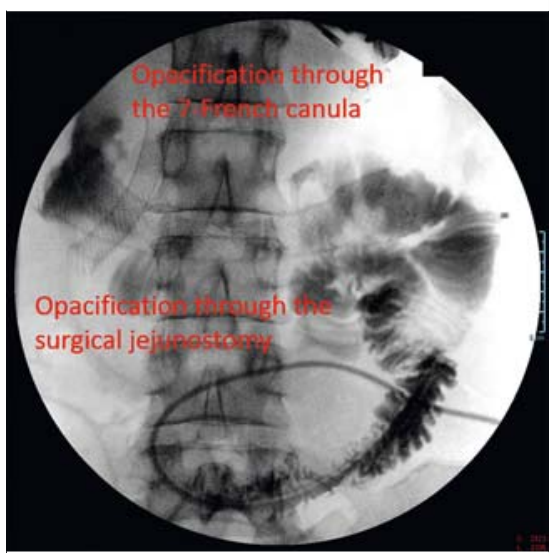

- Fig. 2 Radiographic image after the patient had developed gastric outlet obstruction showing the appearance after contrast injections through a 7-Fr canula placed at the angle of Treitz (using a water-pump) and through the surgical jejunostomy.

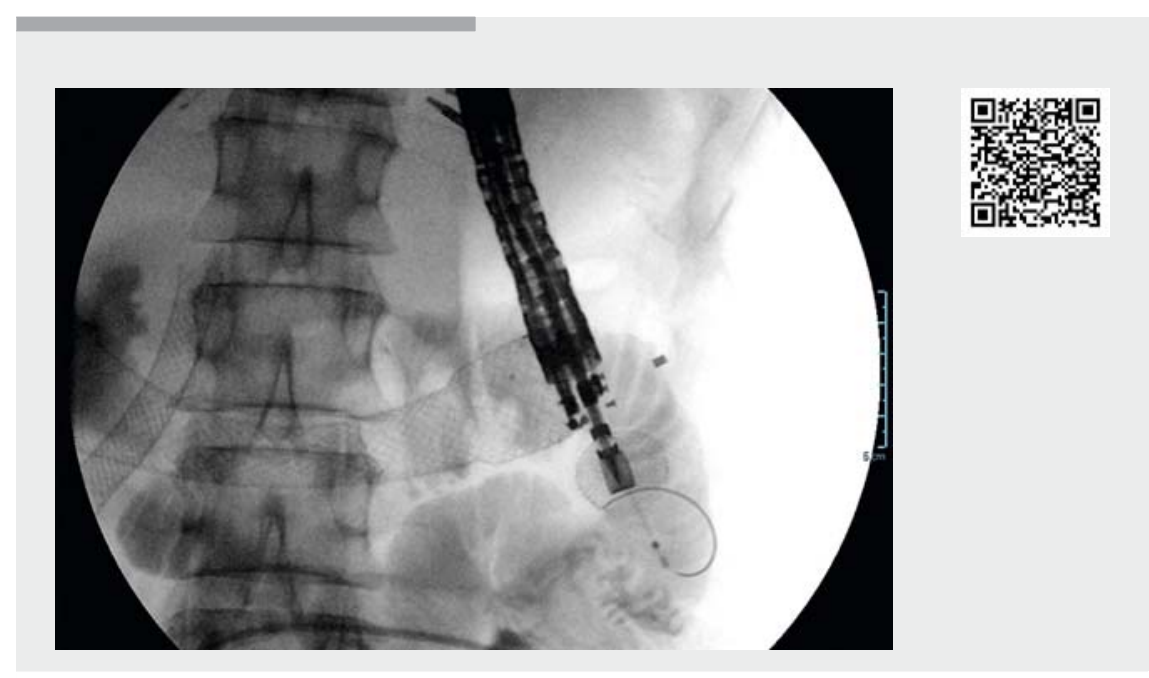

Video 1 Endoscopic ultrasound-guided gastrojejunostomy in a patient with a previous hepaticogastrostomy, antegrade biliary drainage, duodenal stenting, and surgical jejunostomy, who had re-presented with a gastric outlet syndrome due to duodenal stent occlusion.

loaded 0.0035-inch guidewire (Jagwire; Boston Scientific) was performed without complications ( $\triangleright$ Video 1 ).

The patient was able to tolerate an oral solid intake 24 hours later. She underwent an abdominal computed tomog- raphy $(C T)$ scan 1 week later, which confirmed the permeability of the gastrojejunostomy, with no oral contrast passing through the hepaticogastrostomy ( Fig. 3). 

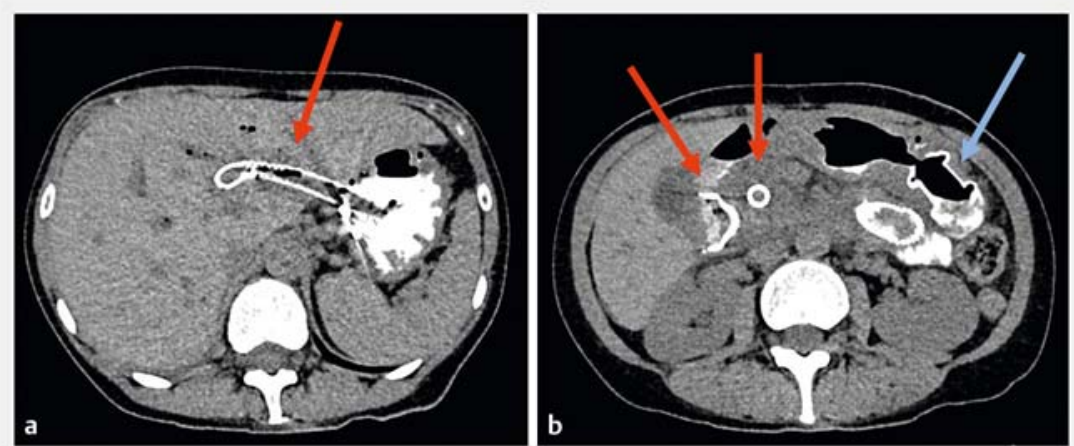

- Fig. 3 Follow-up abdominal computed tomography (CT) scan with oral contrast showing: a no reflux through the hepaticogastrostomy (red arrow); $\mathbf{b}$ the gastrojejunostomy (blue arrow) that was placed in the first jejunal loop a few $\mathrm{cm}$ after the duodenal stent (left-hand red arrow). Note: the occluded biliary stent can also be seen (right-hand red arrow).

Endoscopy_UCTN_Code_TTT_1AS_2AG

\section{Competing interests}

The authors declare that they have no conflict of interest.

The authors

Enrique Pérez-Cuadrado-Robles ${ }^{1}$, Guillaume Perrod ${ }^{1}$, Hédi Benosman', Emilia Ragot ${ }^{2}$, Claire Gallois ${ }^{3}$, Christophe Cellier ${ }^{1}$, Gabriel Rahmi ${ }^{1}$

1 Department of Gastroenterology, GeorgesPompidou European Hospital, AP-HP Centre - Université de Paris, Paris France

2 Department of Digestive Surgery, GeorgesPompidou European Hospital, AP-HP Centre - Université de Paris, Paris France

3 Department of Oncology, GeorgesPompidou European Hospital, AP-HP Centre - Université de Paris, Paris France

\section{Corresponding author}

\section{Enrique Pérez-Cuadrado-Robles, MD}

Service de Gastroentérologie et Endoscopies Digestives, 20 Rue Leblanc, 75015, Paris, France

kikemurcia@gmail.com

\section{References}

[1] Iqbal U, Khara HS, Hu Y et al. EUS-guided gastroenterostomy for the management of gastric outlet obstruction: A systematic review and meta-analysis. Endosc Ultrasound 2020; 9: 16-23

[2] McCarty TR, Garg R, Thompson CC et al. Efficacy and safety of EUS-guided gastroenterostomy for benign and malignant gastric outlet obstruction: a systematic review and meta-analysis. Endosc Int Open 2019; 7: E1474-E1482

\section{Bibliography}

Endoscopy 2021; 53: E143-E144

DOI 10.1055/a-1216-1330

ISSN 0013-726X

published online 5.8.2020

(c) 2020. Thieme. All rights reserved.

Georg Thieme Verlag KG, Rüdigerstraße 14,

70469 Stuttgart, Germany

\section{ENDOSCOPY E-VIDEOS}

https://eref.thieme.de/e-videos

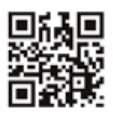

Endoscopy E-Videos is a free access online section, reporting on interesting cases and new

techniques in gastroenterological endoscopy. All papers include a high quality video and all contributions are freely accessible online.

This section has its own submission website at https://mc.manuscriptcentral.com/e-videos 